\title{
Serum Survivin Levels and Outcome of Chemotherapy in Patients with Malignant Mesothelioma
}

\author{
Katja Goričar, ${ }^{1}$ Viljem Kovač, ${ }^{2}$ Alenka Franko, ${ }^{3}$ Metoda Dodič-Fikfak, ${ }^{3}$ and Vita Dolžan ${ }^{1}$ \\ ${ }^{1}$ Pharmacogenetics Laboratory, Institute of Biochemistry, Faculty of Medicine, University of Ljubljana, SI-1000 Ljubljana, Slovenia \\ ${ }^{2}$ Institute of Oncology Ljubljana, SI-1000 Ljubljana, Slovenia \\ ${ }^{3}$ Clinical Institute of Occupational Medicine, University Medical Center Ljubljana, SI-1000 Ljubljana, Slovenia
}

Correspondence should be addressed to Vita Dolžan; vita.dolzan@mf.uni-lj.si

Received 9 July 2015; Revised 4 September 2015; Accepted 6 September 2015

Academic Editor: George Perry

Copyright (C) 2015 Katja Goričar et al. This is an open access article distributed under the Creative Commons Attribution License, which permits unrestricted use, distribution, and reproduction in any medium, provided the original work is properly cited.

\begin{abstract}
Background. Survivin is an inhibitor of apoptosis protein involved in the regulation of cell proliferation that could be used as a marker for cancer diagnosis or prognosis. Our aim was to evaluate whether serum survivin levels influence the outcome of cisplatinbased chemotherapy in patients with malignant mesothelioma (MM). Methods. Serum survivin levels were determined using human survivin enzyme-linked immunosorbent assay in $78 \mathrm{MM}$ patients before chemotherapy, after chemotherapy, and at disease progression. The influence on tumor response and survival was evaluated using nonparametric tests and Cox regression. Results. A median serum survivin level at diagnosis was $4.1(0-217.5) \mathrm{pg} / \mathrm{mL}$. Patients with a progressive disease had significantly higher survivin levels before chemotherapy $(p=0.041)$. A median serum survivin level after chemotherapy was $73.1(0-346.2) \mathrm{pg} / \mathrm{mL}$. If survivin levels increased after chemotherapy, patients had, conversely, better response $(p=0.001, \mathrm{OR}=5.40,95 \% \mathrm{CI}=1.98-14.72)$. Unexpectedly, patients with increased survivin levels after chemotherapy also had longer progression-free $(p<0.001, \mathrm{HR}=0.33$, $95 \% \mathrm{CI}=0.20-0.57)$ and overall survival $(p=0.001, \mathrm{HR}=0.29,95 \% \mathrm{CI}=0.14-0.58)$. Conclusions. These results suggest that serum survivin levels before and during chemotherapy could serve as a biomarker predicting MM treatment response.
\end{abstract}

\section{Introduction}

Survivin is a key member of the inhibitor of the apoptosis protein (IAP) family, encoded by the BIRC5 (baculoviral inhibitor of apoptosis repeat containing 5) gene. Survivin is involved in the regulation of both apoptosis and cell division [1]. IAPs bind and inhibit caspases, reducing their activity and leading to suppression of programmed cell death [2]. The antiapoptotic role of survivin is also exerted through binding and stabilization of X-linked IAP (XIAP) [1, 3].

Survivin is usually not expressed in normal differentiated tissues but is highly expressed in several cancers [1]. The regulation of survivin expression is complex and includes alternative splicing, variability in transcription, or protein degradation and may vary during the cell cycle $[1,4]$. Altered survivin expression in cancer can also be associated with the amplification of BIRC5 locus, different methylation pattern, or differences in promoter activity [1]. Promitotic and antiapoptotic activity of survivin is also linked to its localization in the nucleus or the cytoplasm [5].

Survivin expression allows tumor cells to overcome apoptotic checkpoints and may play an important role in cancer progression $[1,6]$. Survivin has been proposed as a marker not only for diagnosis, but also for prognosis in various cancers [7]. Increased survivin expression is associated with an altered disease outcome or survival in various cancers, but the results differ among studies and cancer types [814]. As several antitumor agents function through apoptosis activation, survivin expression may contribute to the resistance to anticancer agents [1] and could thus help to predict response to chemotherapy [8]. Studies have already shown that inhibition of survivin can sensitize tumor cells to different chemotherapeutic agents including cisplatin [15].

Cisplatin is used in chemotherapy of several cancer types, including malignant mesothelioma (MM). $\mathrm{MM}$ is a rare and aggressive malignancy associated with asbestos exposure 
that has an unfavorable prognosis and short survival. The use of cisplatin-based chemotherapy considerably improved the survival of MM patients [16, 17] and combinations with pemetrexed or gemcitabine had comparable outcomes [16, 18-21]. However, the median survival of MM patients is still short and usually fewer than half of the patients reach complete or partial response after chemotherapy $[16,22]$.

Previous studies in MM evaluated survivin expression in tissue samples or cell lines [23-28]. These studies confirmed both nuclear and cytoplasmic expression of survivin in MM tumors [23, 25-28], but the results regarding the association with the disease outcome were not concordant. Recent studies suggested that even though survivin expression was not associated with overall survival in MM [23], higher survivin expression in MM tumors was observed in patients with a better response to tumor-directed treatment [24].

Due to an increasing incidence of MM and its poor prognosis, new prognostic and predictive biomarkers, preferably noninvasive, are needed, as previously described biomarkers, such as mesothelin and fibulin-3, have only a limited prognostic ability $[29,30]$. As studies in other cancer types already showed that survivin can also be measured in the serum [3135], our aim was to evaluate whether serum survivin levels influence the outcome of cisplatin-based chemotherapy in patients with malignant mesothelioma.

\section{Patients and Methods}

2.1. Patients. This panel study included patients with histologically proven MM treated with cisplatin-based chemotherapy at the Institute of Oncology, Ljubljana, Slovenia, between 1 January 2007 and December 2013. Serum samples were collected before the start of the first day of chemotherapy, after the last cycle of chemotherapy, and at disease progression. Only two samples were collected from patients who did not experience disease progression within the observation period or from patients with disease progression as the immediate outcome of chemotherapy.

Demographic, clinical, and treatment data were obtained from the medical records. Smoking status and exposure to asbestos were obtained during the clinical interview. Regarding exposure to asbestos, patients were classified into the following groups: occupational, environmental, and occasional asbestos exposure or no known asbestos exposure. Informed consent was obtained from all patients. The study was approved by the Slovenian Ethics Committee for Research in Medicine and was carried out according to the Declaration of Helsinki.

2.2. Response and Survival Assessment. The primary outcome of interest was tumor response, evaluated using the modified Response Evaluation Criteria in Solid Tumors (RECIST) [36]. A complete or partial response was considered as a good response, while stable or progressive disease was considered as a poor response. When evaluating the disease control rate, patients with a complete or partial response or stable disease were compared to patients with progressive disease. In the survival analysis, progression-free survival (PFS) and overall survival (OS) were also assessed. PFS was defined as the time from the first day of chemotherapy to the day of documented disease progression, and overall survival (OS) time was defined as the time from the first day of chemotherapy to death from any cause. Patients without progression or death at the time of the analysis were censored at the date of the last follow-up.

2.3. Serum Survivin Level Measurement. Serum samples were prepared immediately after blood sampling, aliquoted, and stored at $-20^{\circ} \mathrm{C}$ until survivin levels were measured. Serum survivin levels were determined using a human survivin enzyme-linked immunosorbent assay (ELISA) kit according to the manufacturer's instructions (Boster Biological Technology, Fremont, CA, USA) blinded regarding the study endpoints.

2.4. Statistical Analyses. To describe central tendency and variability, median and interquartile ranges were used. Nonparametric Kruskal-Wallis and Mann-Whitney tests were used to compare differences in serum survivin concentrations. Pairwise comparisons with post hoc Bonferroni corrections were used to determine which of the treatment outcome groups significantly differed between each other with Kruskal-Wallis test. The Cox proportional hazards model was used to determine the hazard ratios (HR) with the $95 \%$ confidence intervals (CIs) in the survival analysis. The Kaplan-Meier analysis was used to calculate the median survival times. A receiver operating characteristic (ROC) curve was used to analyze the predictive value of survivin and the area under the curve (AUC) was determined. The predicted and observed responses were compared to calculate the specificity, sensitivity, positive predictive value (PPV), and negative predictive value (NPV). The value with the highest sum of sensitivity and specificity was selected as the cutoff. Logistic regression was used to calculate odds ratios and 95\% CIs for determining the influence of categorical variables on the response rate. All statistical analyses were performed using IBM SPSS Statistics, version 19.0 (IBM Corporation, Armonk, NY, USA). All statistical tests were two-sided and the level of significance was set at 0.05.

\section{Results}

In total, $78 \mathrm{MM}$ patients were included in the study. For all patients, pretreatment and posttreatment samples were available. Serum samples at disease progression were available for $61(78.2 \%)$ patients. Median follow-up time was 25.2 months. An additional ten patients experienced disease progression by the time of the analysis; however, samples were not available for the inclusion in the study. Progression therefore occurred in a total of $71(91.0 \%)$ patients, while $42(53.8 \%)$ patients died by the time of the analysis. The patients' characteristics are presented in Table 1.

Serum survivin levels differed considerably among patients. A median serum survivin level was $4.1 \mathrm{pg} / \mathrm{mL}(0-$ $217.5 \mathrm{pg} / \mathrm{mL})$ at diagnosis, $73.1 \mathrm{pg} / \mathrm{mL}(0-346.2 \mathrm{pg} / \mathrm{mL})$ after chemotherapy, and $28.3 \mathrm{pg} / \mathrm{mL}(0-366.9 \mathrm{pg} / \mathrm{mL})$ at disease 
TABle 1: Patients' characteristics.

\begin{tabular}{|c|c|c|}
\hline Characteristic & $\begin{array}{l}\text { All patients }(N=78) \\
\qquad(\%)\end{array}$ & $\begin{array}{c}\text { Exposed to asbestos }(N=63) \\
\qquad N(\%)\end{array}$ \\
\hline \multicolumn{3}{|l|}{ Gender } \\
\hline Male & $66(84.6)$ & $54(85.7)$ \\
\hline Female & $12(15.4)$ & $9(14.3)$ \\
\hline \multicolumn{3}{|l|}{ Age } \\
\hline Years, median (25-75\%) & $64.0(57.8-70.3)$ & $65.0(58.0-70.0)$ \\
\hline \multicolumn{3}{|l|}{ Asbestos exposure } \\
\hline Exposed & $63(80.8)$ & $63(100.0)$ \\
\hline Unexposed & $15(19.2)$ & \\
\hline \multicolumn{3}{|l|}{ Smoking } \\
\hline Nonsmokers & $36(46.2)$ & $30(47.6)$ \\
\hline Smokers & $42(53.8)$ & $33(52.4)$ \\
\hline \multicolumn{3}{|l|}{ Stage } \\
\hline I & $6(7.7)$ & $6(9.5)$ \\
\hline II & $21(26.9)$ & $17(27.0)$ \\
\hline III & $26(33.3)$ & $19(30.2)$ \\
\hline IV & $18(23.1)$ & $17(27.0)$ \\
\hline Peritoneal & $7(9.0)$ & $4(6.3)$ \\
\hline \multicolumn{3}{|l|}{ Histological type } \\
\hline Epitheloid & $60(76.9)$ & $48(76.2)$ \\
\hline Biphasic & $11(14.1)$ & $10(15.9)$ \\
\hline Sarcomatoid & $4(5.1)$ & $3(4.8)$ \\
\hline Not characterized & $3(3.8)$ & $2(3.2)$ \\
\hline \multicolumn{3}{|c|}{ Eastern Cooperative Oncology Group performance status } \\
\hline 0 & $33(42.3)$ & $28(44.4)$ \\
\hline 1 & $26(33.3)$ & $21(33.3)$ \\
\hline 2 & $19(24.4)$ & $14(22.2)$ \\
\hline \multicolumn{3}{|l|}{ CRP } \\
\hline mg/L, median (25-75\%) & $21(6-62)$ & $22(6-58)$ \\
\hline \multicolumn{3}{|l|}{ First-line chemotherapy } \\
\hline Gemcitabine and cisplatin & $53(67.9)$ & $43(68.3)$ \\
\hline Pemetrexed and cisplatin & $25(32.1)$ & $20(31.7)$ \\
\hline \multicolumn{3}{|l|}{ Response rate ${ }^{*}$} \\
\hline $\mathrm{CR}$ or $\mathrm{PR}$ & $29(37.7)$ & $23(37.1)$ \\
\hline SD or progress & $48(62.3)$ & $39(62.9)$ \\
\hline \multicolumn{3}{|l|}{ Overall survival } \\
\hline Months, median (25-75\%) & $20.0(11.6-47.8)$ & $18.0(11.6-28.7)$ \\
\hline \multicolumn{3}{|l|}{ Progression-free survival } \\
\hline Months, median (25-75\%) & $7.9(5.6-13.9)$ & $7.8(5.6-13.1)$ \\
\hline
\end{tabular}

* Data missing for 1 patient; CR: complete response; N: number of patients; PR: partial response; SD: stable disease.

progression. In $35(44.9 \%)$ patients, serum survivin levels increased after cisplatin-based chemotherapy. The median change of survivin levels after chemotherapy was $0 \mathrm{pg} / \mathrm{mL}$ $(-4.1$ to $113.7 \mathrm{pg} / \mathrm{mL})$. At disease progression, serum survivin levels were also higher compared to baseline in $22(36.1 \%)$ out of 61 patients; the median change was $0 \mathrm{pg} / \mathrm{mL}(0-$ $81.6 \mathrm{pg} / \mathrm{mL})$.

We also compared serum survivin levels at diagnosis among patients with different clinical characteristics. MM patients without known asbestos exposure had significantly higher serum survivin levels at diagnosis (Mann-Whitney $U$ $=270.0, p=0.006): 303.8 \mathrm{pg} / \mathrm{mL}(0-2432.7 \mathrm{pg} / \mathrm{mL})$ compared to $0 \mathrm{pg} / \mathrm{mL}(0-87.4 \mathrm{pg} / \mathrm{mL})$ in patients exposed to asbestos. Further analyses were therefore performed separately also for the cohort of patients exposed to asbestos.

3.1. Treatment Outcome. Survivin levels before chemotherapy and a change in survivin levels after chemotherapy are presented in Table 2. Higher serum survivin levels before chemotherapy were observed in patients with a worse disease 
TABLE 2: Survivin levels before chemotherapy and change in survivin levels after chemotherapy and MM treatment outcome.

\begin{tabular}{lcccc}
\hline & $\begin{array}{c}\text { Survivin levels before chemotherapy (pg/mL, median } \\
(25 \% \text { to } 75 \%)) \\
\text { Treatment outcome }\end{array}$ & $\begin{array}{c}\text { All patients } \\
(N=77)\end{array}$ & $\begin{array}{c}\text { Patients exposed to asbestos } \\
(N=62)\end{array}$ & $\begin{array}{c}\text { Change in survivin levels (pg/mL, median } \\
(25 \% \text { to } 75 \%)) \\
\text { Patients exposed to asbestos } \\
(N=62)\end{array}$ \\
\hline Complete response & $0(0-37.0)$ & $0(0-37.0)$ & $114.3(6.0$ to 304.5$)$ & $114.3(6.0$ to 304.5$)$ \\
Partial response & $33.9(0-803.4)$ & $4.1(0-174.8)$ & $61.6(0$ to 163.9$)$ & $62.2(0$ to 110.3$)$ \\
Stable disease & $0(0-124.9)$ & $0(0-71.9)$ & $0(-2.0$ to 66.9$)$ & $0(-4.1$ to 55.3$)$ \\
Progress & $199.7(38.0-3102.7)$ & $166.9(62.0-2377.0)$ & $-45.2(-975.4$ to 0$)$ & $-88.6(-1370.9$ to -39.8$)$ \\
Kruskal-Wallis test statistic & 7.951 & 6.561 & 8.892 & 14.365 \\
$p$ value & 0.047 & 0.087 & 0.031 & 0.002 \\
\hline
\end{tabular}

$N$ : number of patients.

TABLE 3: Change in survivin levels after chemotherapy and response rate.

\begin{tabular}{lcccc}
\hline & \multicolumn{2}{c}{ All patients $(N=77)$} & \multicolumn{2}{c}{ Patients exposed to asbestos $(N=62)$} \\
Observed response & Decreased survivin levels & Increased survivin levels & Decreased survivin levels & Increased survivin levels \\
& $N(\%)$ & $N(\%)$ & $6(\%)$ & $N(\%)$ \\
\hline CR + PR & $9(20.9)$ & $20(58.8)$ & $6(17.1)$ & $17(63.0)$ \\
SD + PD & $34(79.1)$ & $14(41.2)$ & $29(82.9)$ & $10(37.0)$ \\
\hline
\end{tabular}

CR: complete response; $N$ : number of patients; PR: partial response; SD: stable disease.

outcome (Kruskal-Wallis test statistic $=7.951, p=0.047$, Table 2). Patients who experienced disease progression during chemotherapy had higher survivin levels compared to patients with disease control (Mann-Whitney $U=354.0, p=$ 0.041) and this difference was more pronounced if only patients exposed to asbestos were evaluated (Mann-Whitney $U=190.0, p=0.021$ ).

Patients with increased serum survivin levels had a better response to platinum-based chemotherapy, while serum survivin levels decreased in patients with progressive disease (Kruskal-Wallis test statistic $=8.892, p=0.031$, Table 2). This observation was even more significant if only patients exposed to asbestos were evaluated (Kruskal-Wallis test statistic $=14.365, p=0.002$, Table 2). Differences between a progressive disease and a complete response and between a progressive disease and a partial response remained significant after Bonferroni correction (Kruskal-Wallis test statistic = 39.500 and 31.579 , adjusted $p=0.010$ and 0.007 , resp.).

A median change in the serum survivin level was $61.6 \mathrm{pg} / \mathrm{mL}(0-215.4 \mathrm{pg} / \mathrm{mL})$ in patients with a good response and $0 \mathrm{pg} / \mathrm{mL}(-34.4-54.3 \mathrm{pg} / \mathrm{mL})$ in patients with a poor response. When comparing patients with a good and poor response, significant differences in the change in the serum survivin level after chemotherapy were observed in the whole patient cohort and among patients exposed to asbestos (Mann-Whitney $U=908.0, p=0.024$, and Mann-Whitney $U$ =643.0, $p=0.004$, resp.). Similarly, the change in survivin levels differed significantly between patients with progressive disease and patients with disease control (Mann-Whitney $U=$ 123.0, $p=0.028$, for all patients, and Mann-Whitney $U=18.0$, $p=0.004$, for patients exposed to asbestos).

To determine the cutoff value for the change of the serum survivin level after chemotherapy, we calculated the specificity and sensitivity of predicting the response rate. The cutoff value was 0 and patients with an increase in survivin levels had 5.40 times greater odds for a good response than patients with a decrease in survivin levels $(p=0.001, \mathrm{OR}=$ $5.40,95 \% \mathrm{CI}=1.98-14.72)$. When all patients were assessed, this cutoff had a specificity of 0.708 and sensitivity of 0.690 , while PPV was 0.588 and NPV was 0.791 (Table 3). Among asbestos exposed patients, the AUC for the change in survivin levels predicting the response rate was 0.717 (95\% CI $=0.580-$ 0.854 ) ( $p=0.005$, Figure 1$)$. At the cutoff value of 0 , the specificity was 0.744 and sensitivity was 0.739 , while PPV was 0.630 and NPV was 0.829 (Table 3 ). If serum survivin levels increased after chemotherapy, patients had 8.22 times greater odds for a good response $(p<0.001, \mathrm{OR}=8.22,95 \% \mathrm{CI}=$ 2.54-26.63).

3.2. Survival Analysis. A higher serum survivin level before chemotherapy did not have a substantial effect on PFS among all patients $(p=0.202, \mathrm{HR}=1.01,95 \% \mathrm{CI}=0.99-1.04$, for a survivin increase of $100 \mathrm{pg} / \mathrm{mL}$ ) or patients exposed to asbestos $(p=0.046, \mathrm{HR}=1.03,95 \% \mathrm{CI}=1.00-1.05$, for a survivin increase of $100 \mathrm{pg} / \mathrm{mL})$. Additionally, there was no association with OS ( $p=0.444$ for all patients and $p=0.194$ for patients exposed to asbestos).

We compared patients with increased survivin levels after chemotherapy compared to pretreatment levels to patients with unchanged or decreased levels in the survival analysis. Patients with increased survivin levels after chemotherapy had significantly longer PFS both in the whole cohort of patients and in the subgroup exposed to asbestos $(p<$ $0.001, \mathrm{HR}=0.33,95 \% \mathrm{CI}=0.20-0.57$, Figure $2(\mathrm{a})$, and $p=$ $0.002, \mathrm{HR}=0.40,95 \% \mathrm{CI}=0.22-0.71$, resp.). Similarly, 


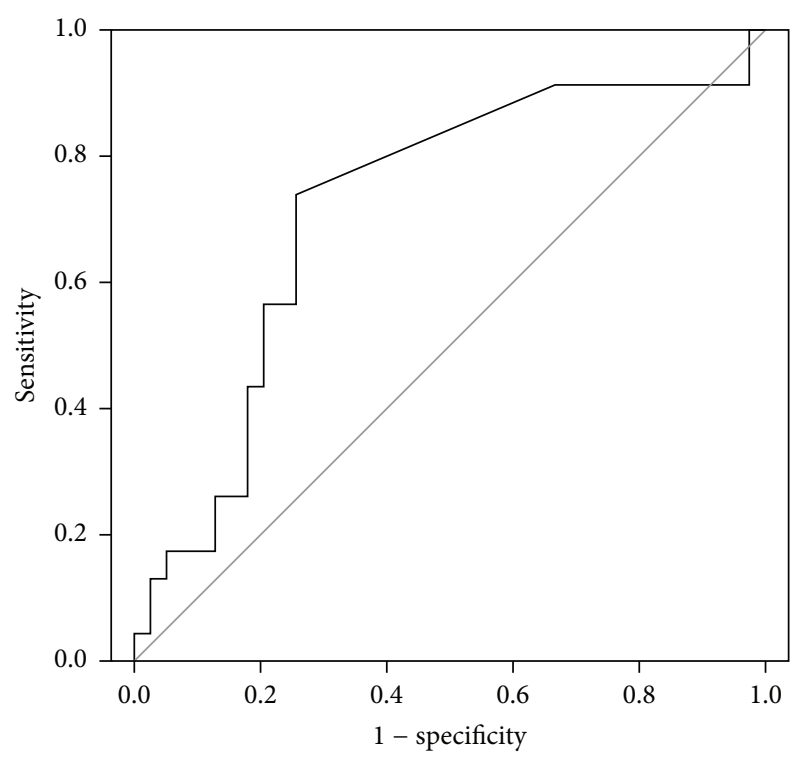

FIGURE 1: Receiver operating characteristic curve for the change in survivin levels predicting the response rate in malignant mesothelioma patients.

increased survivin levels were also associated with longer OS in the whole cohort $(p=0.001, \mathrm{HR}=0.29,95 \% \mathrm{CI}=$ $0.14-0.58$, Figure $2(\mathrm{~b})$ ) and among patients with known asbestos exposure $(p=0.008, \mathrm{HR}=0.35,95 \% \mathrm{CI}=0.16-$ $0.77)$. In the whole cohort of patients, those with decreased survivin levels had median PFS of 6.7 (5.2-9.6) months and median OS of 15.1 (10.0-22.0) months, compared to 13.1 (2.8-23.8) months and $47.8(16.3-47.8)$ months in patients with increased survivin after chemotherapy. In the asbestos exposed patients, the ones with decreased survivin levels had median PFS of 6.7 (5.2-9.6) months and median OS of 15.1 (11.0-21.0) months, compared to $10.4(6.5-23.8)$ months and 47.8 (18.0-47.8) months in patients with increased survivin after chemotherapy.

Regarding the change in survivin levels at disease progression, we only evaluated their influence on OS: if survivin levels increased compared to baseline, patients had significantly longer overall survival ( $p=0.001, \mathrm{HR}=0.84,95 \% \mathrm{CI}=$ $0.76-0.93$, for survivin increase of $100 \mathrm{pg} / \mathrm{mL}$ ); however, only a trend towards longer OS was seen in the subgroup exposed to asbestos $(p=0.092, \mathrm{HR}=0.88,95 \% \mathrm{CI}=0.67-1.02$, for a survivin increase of $100 \mathrm{pg} / \mathrm{mL}$ ).

\section{Discussion}

In the present study, we evaluated serum survivin levels in MM patients before and after cisplatin-based chemotherapy. Patients with higher survivin levels before chemotherapy tended to have a worse treatment outcome; if the levels increased after chemotherapy, the results show the opposite direction: patients had a better treatment outcome and longer PFS and OS.

Survivin is an interesting potential biomarker in cancer due to its role in the regulation of apoptosis and cell division
[1] as inhibition of apoptosis could contribute to cancer progression, but it could also affect cancer treatment. Several studies therefore investigated whether it could be used as a prognostic or predictive biomarker in MM. The first studies in MM showed that survivin mRNA levels were significantly higher in pleural MM tissue and inflammatory tissue [25], but the association with the disease outcome was not the same in all studies. Survivin positive tumors were associated with shorter survival in one of the studies [26], but other studies showed no association with the disease outcome [23, 27]. Conversely, patients treated with chemotherapy alone in combination with radiotherapy or surgery had significantly higher tumor survivin expression than patients that received the best supportive care or palliative treatment or were not treated at all [24]. These observations are in accordance with the data showing that the treatment with cisplatin leads to increased survivin expression in MM cell lines [37]. Additionally, even though higher nuclear survivin expression in tumor samples or BIRC5 polymorphisms was not related to OS in all patients regardless of the treatment [23], higher survivin expression was related to a better treatment outcome in patients treated with chemotherapy [24]. The latter is in accordance with our results, where patients with increased survivin expression after chemotherapy had a better response to chemotherapy and longer survival.

Previous studies investigating serum survivin levels in other malignancies focused mostly on levels at diagnosis and comparison to healthy individuals [31-35]. Consistently, survivin levels were higher in patients compared to controls, even though the difference was not always statistically significant. In ovarian cancer, gallbladder cancer, and pancreatic ductal adenocarcinoma, higher pretreatment levels of survivin were also associated with shorter survival [3335]. In accordance with these results, patients with higher serum survivin levels at diagnosis also tended to have a worse outcome in our study. On the other hand, only two studies compared survivin levels before and after treatment: no difference was observed in breast cancer or non-small cell lung cancer, but the association between a change in expression and a treatment outcome was not examined [32, 38].

Most of the other studies focused on survivin expression in the tumor at diagnosis, where it was usually regarded as a marker of a poor response. For example, survivin negative tumors were associated with better survival rates in several cancer types, including bladder cancer, colorectal cancer, medulloblastoma, and glioma [8, 11-13]. But the results of several studies suggest that survivin has a more complex role in cancer, as higher survivin expression was also often associated with a favorable outcome [14, 39-43]. In most of these studies, the nuclear and cytoplasmic localization of survivin was assessed separately as it might influence its antiapoptotic activity [5]. Nuclear expression was generally associated with longer survival [40-42]. In studies focused on specific cancer treatment, higher survivin expression in tumor was associated with a better response to radiotherapy and longer survival in head and neck or oral squamous cell carcinoma [14, 39]. In cell lines, survivin silencing also led to decreased sensitivity to radiation [14]. In non-small cell lung 


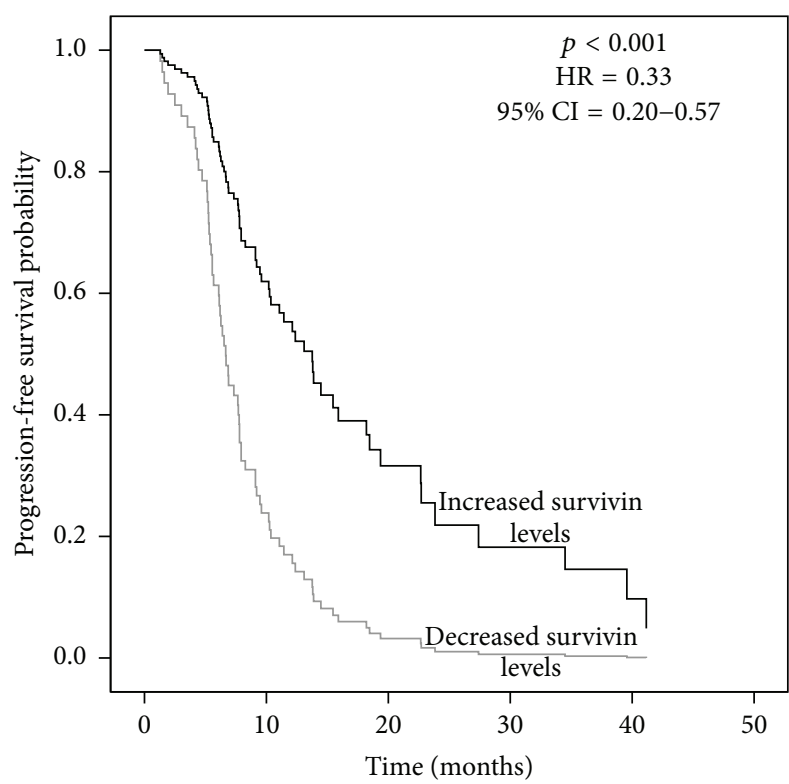

(a)

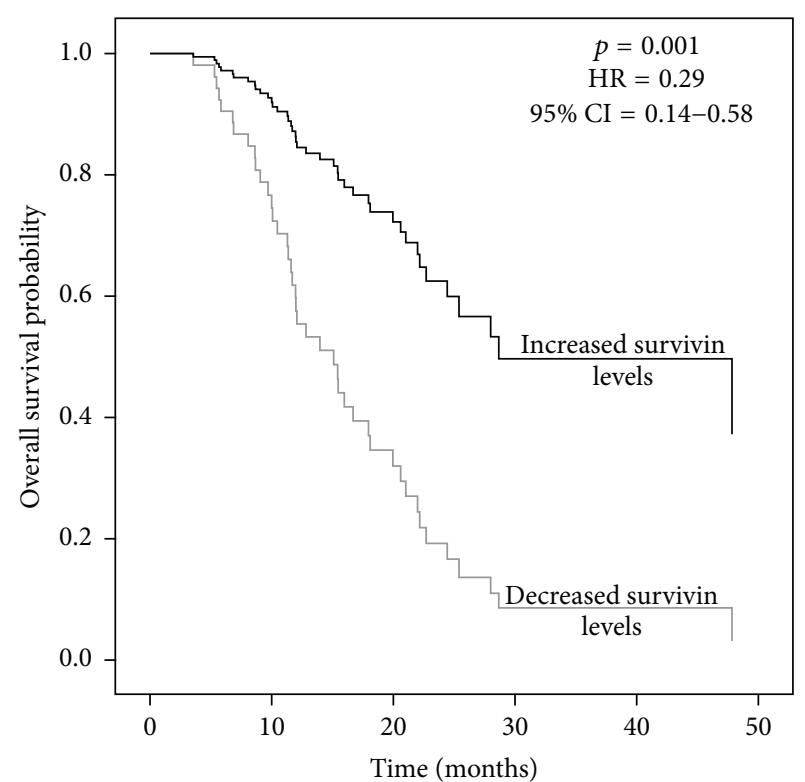

(b)

FIGURE 2: Change in serum survivin levels after chemotherapy is associated with (a) progression-free survival and (b) overall survival of malignant mesothelioma patients.

cancer, higher nuclear survivin expression was also associated with longer survival after chemotherapy [43], which is also in agreement with our results suggesting that higher survivin levels after chemotherapy may be associated with a better treatment response. On the other hand, the opposite effect was observed in other studies where survivin silencing increased the sensitivity to chemotherapy or radiation [44], further suggesting that survivin might have additional molecular functions. The biological basis for the role of survivin in the treatment response is still not well established. It was proposed that high survivin expression might be associated with higher susceptibility to DNA damage induced by cancer treatment [39]. Recent studies show that survivin interacts with components of DNA double-strand break repair and might regulate DNA repair [44]. Moreover, induction of DNA damage leads to increased survivin expression [45]. Different functions of survivin could help to explain the results of a study on breast cancer, where high survivin levels were associated with a poor response to endocrine treatment, but a good response to chemotherapy [46].

Differences in survivin localization, as well as cancer type and cancer treatment, might therefore affect the role of survivin expression in cancer diagnosis and prognosis. Consequently, careful selection of tumor or serum biomarkers, determination of appropriate cutoff values, and validation of the results are very important before the implementation in the clinical practice. In our pilot study, we focused on serum survivin levels as they are easily determined using a noninvasive approach and amenable to follow-up. ELISA was selected as an appropriate method for serum survivin detection. As a commercially available kit was used, we did not validate the results with other methods, which represents a limitation of our study. Previous studies show that different commercially available kits may have different sensitivity; however, in their setting, no difference was observed between cancer patients and controls in regard to the levels of serum survivin detected by two different ELISA kits [47]. Before potential implementation in the clinical practice, further studies should therefore validate which commercially available assays are the most sensitive and reliable in the detection of a serum pool of survivin in MM patients and have higher predictive values in serum samples.

We were the first to assess the changes in serum survivin during treatment and show that increased survivin levels after chemotherapy were a marker of a better treatment outcome in MM, emphasizing the importance of survivin measurement before and after chemotherapy. Our sample size was comparable to other studies or even bigger, especially taking into account the rarity of MM. In the survival analysis, we were able to detect with $80 \%$ power differences in HR of approximately 0.5 or lower. However, our results need to be confirmed in an independent patient cohort.

Even though the role of survivin in cancer treatment is complex, our results suggest that measurement of serum survivin levels before and during chemotherapy could serve as a noninvasive biomarker predicting a response to treatment in $\mathrm{MM}$, potentially contributing to a better treatment outcome in these patients.

\section{Conflict of Interests}

The authors declare that there is no conflict of interests regarding the publication of this paper. 


\section{Acknowledgments}

The authors thank Barbara Možina, M.S., Head of the Biochemistry Laboratory, Institute of Oncology Ljubljana, Slovenia, for her help with blood sample collection and handling. Special thanks are due to Alenka Vrbinc and Marjeta Vrbinc for editing the paper as carefully as they always do. This work was financially supported by the Slovenian Research Agency (Grants L3-3648 and P1-0170).

\section{References}

[1] A. C. Mita, M. M. Mita, S. T. Nawrocki, and F. J. Giles, "Survivin: key regulator of mitosis and apoptosis and novel target for cancer therapeutics," Clinical Cancer Research, vol. 14, no. 16, pp. 5000-5005, 2008.

[2] A. D. Schimmer, "Inhibitor of apoptosis proteins: translating basic knowledge into clinical practice," Cancer Research, vol. 64, no. 20, pp. 7183-7190, 2004.

[3] T. Dohi, F. Xia, and D. C. Altieri, "compartmentalized phosphorylation of iap by protein kinase a regulates cytoprotection," Molecular Cell, vol. 27, no. 1, pp. 17-28, 2007.

[4] B. M. Ryan, N. O’Donovan, and M. J. Duffy, "Survivin: a new target for anti-cancer therapy," Cancer Treatment Reviews, vol. 35, no. 7, pp. 553-562, 2009.

[5] R. H. Stauber, W. Mann, and S. K. Knauer, "Nuclear and cytoplasmic survivin: molecular mechanism, prognostic, and therapeutic potential," Cancer Research, vol. 67, no. 13, pp. 59996002, 2007.

[6] B. Nachmias, Y. Ashhab, and D. Ben-Yehuda, “The inhibitor of apoptosis protein family (IAPs): an emerging therapeutic target in cancer," Seminars in Cancer Biology, vol. 14, no. 4, pp. 231-243, 2004.

[7] D. Derin, H. O. Soydinç, N. Guney et al., "Serum levels of apoptosis biomarkers, survivin and TNF-alpha in nonsmall cell lung cancer," Lung Cancer, vol. 59, no. 2, pp. 240-245, 2008.

[8] A. B. Als, L. Dyrskjøt, H. von der Maase et al., "Emmprin and survivin predict response and survival following cisplatincontaining chemotherapy in patients with advanced bladder cancer," Clinical Cancer Research, vol. 13, no. 15, part 1, pp. 44074414, 2007.

[9] H. Kawasaki, D. C. Altieri, C.-D. Lu, M. Toyoda, T. Tenjo, and N. Tanigawa, "Inhibition of apoptosis by survivin predicts shorter survival rates in colorectal cancer," Cancer Research, vol. 58, no. 22, pp. 5071-5074, 1998.

[10] M. Monzó, R. Rosell, E. Felip et al., "A novel anti-apoptosis gene: re-expression of survivin messenger RNA as a prognosis marker in non-small-cell lung cancers," Journal of Clinical Oncology, vol. 17, no. 7, pp. 2100-2104, 1999.

[11] J. Pizem, A. Cör, L. Zadravec-Zaletel, and M. Popovic, "Survivin is a negative prognostic marker in medulloblastoma," Neuropathology and Applied Neurobiology, vol. 31, no. 4, pp. 422-428, 2005.

[12] A. I. Sarela, R. C. A. Macadam, S. M. Farmery, A. F. Markham, and P. J. Guillou, "Expression of the antiapoptosis gene, survivin, predicts death from recurrent colorectal carcinoma," Gut, vol. 46, no. 5, pp. 645-650, 2000.

[13] M. Uematsu, I. Ohsawa, T. Aokage et al., "Prognostic significance of the immunohistochemical index of survivin in glioma: a comparative study with the MIB-1 index," Journal of NeuroOncology, vol. 72, no. 3, pp. 231-238, 2005.
[14] L. Farnebo, K. Tiefenböck, A. Ansell, L. K. Thunell, S. Garvin, and K. Roberg, "Strong expression of survivin is associated with positive response to radiotherapy and improved overall survival in head and neck squamous cell carcinoma patients," International Journal of Cancer, vol. 133, no. 8, pp. 1994-2003, 2013.

[15] N. Zaffaroni and M. G. Daidone, "Survivin expression and resistance to anticancer treatments: perspectives for new therapeutic interventions," Drug Resistance Updates, vol. 5, no. 2, pp. 65-72, 2002.

[16] V. Kovac, M. Zwitter, and T. Zagar, "Improved survival after introduction of chemotherapy for malignant pleural mesothelioma in Slovenia: population-based survey of 444 patients," Radiology and Oncology, vol. 46, no. 2, pp. 136-144, 2012.

[17] R. A. M. Damhuis, C. Schroten, and J. A. Burgers, "Populationbased survival for malignant mesothelioma after introduction of novel chemotherapy," European Respiratory Journal, vol. 40, no. 1, pp. 185-189, 2012.

[18] V. Kovac, M. Zwitter, M. Rajer et al., "A phase II trial of low-dose gemcitabine in a prolonged infusion and cisplatin for malignant pleural mesothelioma," Anti-Cancer Drugs, vol. 23, no. 2, pp. 230-238, 2012.

[19] C. W. Lee, N. Murray, H. Anderson, S. C. Rao, and W. Bishop, "Outcomes with first-line platinum-based combination chemotherapy for malignant pleural mesothelioma: a review of practice in British Columbia," Lung Cancer, vol. 64, no. 3, pp. 308-313, 2009.

[20] N. J. Vogelzang, J. J. Rusthoven, J. Symanowski et al., "Phase III study of pemetrexed in combination with cisplatin versus cisplatin alone in patients with malignant pleural mesothelioma," Journal of Clinical Oncology, vol. 21, no. 14, pp. 2636-2644, 2003.

[21] K. Goricar, V. Kovac, and V. Dolzan, "Polymorphisms in folate pathway and pemetrexed treatment outcome in patients with malignant pleural mesothelioma," Radiology and Oncology, vol. 48, no. 2, pp. 163-172, 2014.

[22] Å. Helland, S. Solberg, and O. T. Brustugun, "Incidence and survival of malignant pleural mesothelioma in Norway: a population-based study of 1686 cases," Journal of Thoracic Oncology, vol. 7, no. 12, pp. 1858-1861, 2012.

[23] J. Hmeljak, N. Erčulj, V. Dolžan, I. Kern, and A. Cör, "BIRC5 promoter SNPs do not affect nuclear survivin expression and survival of malignant pleural mesothelioma patients," Journal of Cancer Research and Clinical Oncology, vol. 137, no. 11, pp. 16411651, 2011.

[24] J. Hmeljak, N. Erčulj, V. Dolžan et al., "Is survivin expression prognostic or predictive in malignant pleural mesothelioma?" Virchows Archiv, vol. 462, no. 3, pp. 315-321, 2013.

[25] M. Falleni, C. Pellegrini, A. Marchetti et al., "Quantitative evaluation of the apoptosis regulating genes Survivin, Bcl-2 and Bax in inflammatory and malignant pleural lesions," Lung Cancer, vol. 48, no. 2, pp. 211-216, 2005.

[26] G. J. Gordon, M. Mani, L. Mukhopadhyay et al., "Expression patterns of inhibitor of apoptosis proteins in malignant pleural mesothelioma," The Journal of Pathology, vol. 211, no. 4, pp. 447454, 2007.

[27] L. Kleinberg, A. K. Lie, V. A. Flørenes, J. M. Nesland, and B. Davidson, "Expression of inhibitor-of-apoptosis protein family members in malignant mesothelioma," Human Pathology, vol. 38, no. 7, pp. 986-994, 2007.

[28] N. Zaffaroni, A. Costa, M. Pennati et al., "Survivin is highly expressed and promotes cell survival in malignant peritoneal 
mesothelioma," Cellular Oncology, vol. 29, no. 6, pp. 453-466, 2007.

[29] A. Franko, V. Dolzan, V. Kovac, N. Arneric, and M. DodicFikfak, "Soluble mesothelin-related peptides levels in patients with malignant mesothelioma," Disease Markers, vol. 32, no. 2, pp. 123-131, 2012.

[30] V. Kovac, M. Dodic-Fikfak, N. Arneric, V. Dolzan, and A. Franko, "Fibulin-3 as a biomarker of response to treatment in malignant mesothelioma," Radiology and Oncology, vol. 49, no. 3, pp. 279-285, 2015.

[31] A. Fawzy, R. Gaafar, F. Kasem, S. S. Ali, M. Elshafei, and M. Eldeib, "Importance of serum levels of angiopoietin-2 and survivin biomarkers in non-small cell lung cancer," Journal of the Egyptian National Cancer Institute, vol. 24, no. 1, pp. 41-45, 2012.

[32] N. Guney, H. O. Soydine, D. Derin et al., "Serum and urine survivin levels in breast cancer," Medical Oncology, vol. 23, no. 3, pp. 335-339, 2006.

[33] B. Dobrzycka, B. Mackowiak-Matejczyk, K. M. Terlikowska, B. Kulesza-Bronczyk, M. Kinalski, and S. J. Terlikowski, "Serum levels of IL-6, IL-8 and CRP as prognostic factors in epithelial ovarian cancer," European Cytokine Network, vol. 24, no. 3, pp. 106-113, 2013.

[34] J. Nigam, A. Chandra, H. R. Kazmi et al., "Expression of serum survivin protein in diagnosis and prognosis of gallbladder cancer: a comparative study," Medical Oncology, vol. 31, no. 9, article 167, 2014.

[35] Y. Q. Ren, H. Y. Zhang, T. Su, X. H. Wang, and L. Zhang, "Clinical significance of serum survivin in patients with pancreatic ductal adenocarcinoma," European Review for Medical and Pharmacological Sciences, vol. 18, no. 20, pp. 3063-3068, 2014.

[36] M. J. Byrne and A. K. Nowak, "Modified RECIST criteria for assessment of response in malignant pleural mesothelioma," Annals of Oncology, vol. 15, no. 2, pp. 257-260, 2004.

[37] S. Ozimič, J. Hmeljak, and A. Cör, "Survivin expression in response to cisplatin-induced stress," in Book of Abstracts7th Conference on Experimental and Translational Oncology, G. Serša, J. Kos, T. L. Turnšek et al., Eds., p. 122, Association of Radiology and Oncology, Portorož, Slovenia, 2013.

[38] W. Naumnik, W. Nilklińska, M. Ossolińska, and E. Chyczewska, "Serum levels of HMGB1, survivin, and VEGF in patients with advanced non-small cell lung cancer during chemotherapy," Folia Histochemica et Cytobiologica, vol. 47, no. 4, pp. 703-709, 2009.

[39] K. Freier, S. Pungs, C. Sticht et al., "High survivin expression is associated with favorable outcome in advanced primary oral squamous cell carcinoma after radiation therapy," International Journal of Cancer, vol. 120, no. 4, pp. 942-946, 2007.

[40] S. M. Kennedy, L. O’Driscoll, R. Purcell et al., "Prognostic importance of survivin in breast cancer," British Journal of Cancer, vol. 88, no. 7, pp. 1077-1083, 2003.

[41] T. Ponnelle, C. Chapusot, L. Martin et al., "Cellular localisation of survivin: impact on the prognosis in colorectal cancer," Journal of Cancer Research and Clinical Oncology, vol. 131, no. 8, pp. 504-510, 2005.

[42] K. Trieb, R. Lehner, T. Stulnig, I. Sulzbacher, and K. R. Shroyer, "Survivin expression in human osteosarcoma is a marker for survival," European Journal of Surgical Oncology, vol. 29, no. 4, pp. 379-382, 2003.

[43] B. Vischioni, P. van der Valk, S. W. Span, F. A. E. Kruyt, J. A. Rodriguez, and G. Giaccone, "Nuclear localization of survivin is a positive prognostic factor for survival in advanced non-smallcell lung cancer," Annals of Oncology, vol. 15, no. 11, pp. 16541660, 2004.

[44] S. Reichert, C. Rödel, J. Mirsch et al., "Survivin inhibition and DNA double-strand break repair: a molecular mechanism to overcome radioresistance in glioblastoma," Radiotherapy \& Oncology, vol. 101, no. 1, pp. 51-58, 2011.

[45] B. Unruhe, E. Schröder, D. Wünsch, and S. K. Knauer, "An old flame never dies: survivin in cancer and cellular senescence," Gerontology, 2015.

[46] P. N. Span, V. C. G. Tjan-Heijnen, P. Manders, D. Van Tienoven, J. Lehr, and F. C. G. J. Sweep, "High survivin predicts a poor response to endocrine therapy, but a good response to chemotherapy in advanced breast cancer," Breast Cancer Research and Treatment, vol. 98, no. 2, pp. 223-230, 2006.

[47] X. Jia, Y. Gao, D. Zhai et al., "Survivin is not a promising serological maker for the diagnosis of hepatocellular carcinoma," Oncology Letters, vol. 9, no. 5, pp. 2347-2352, 2015. 


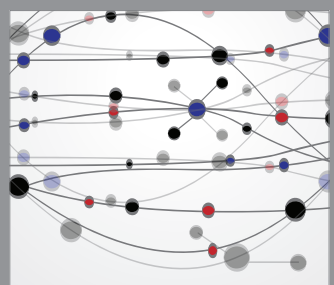

The Scientific World Journal
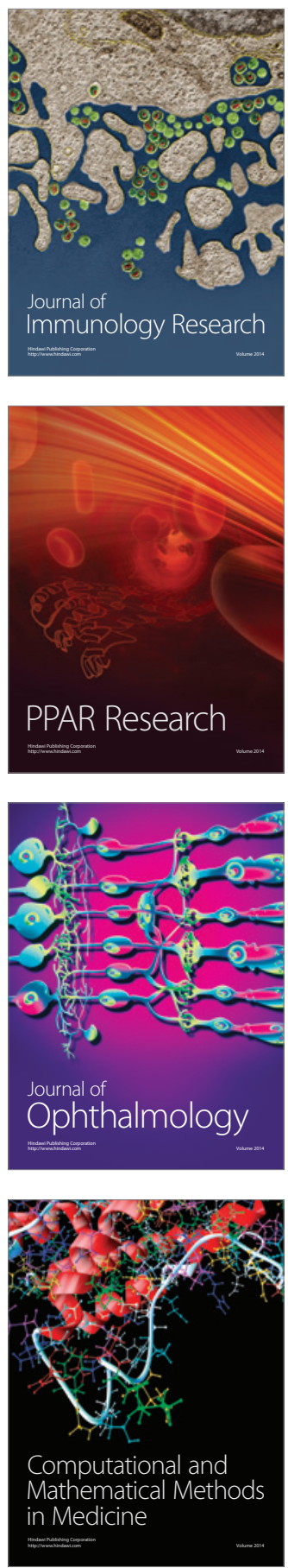

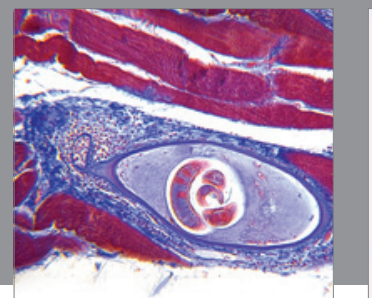

Gastroenterology

Research and Practice
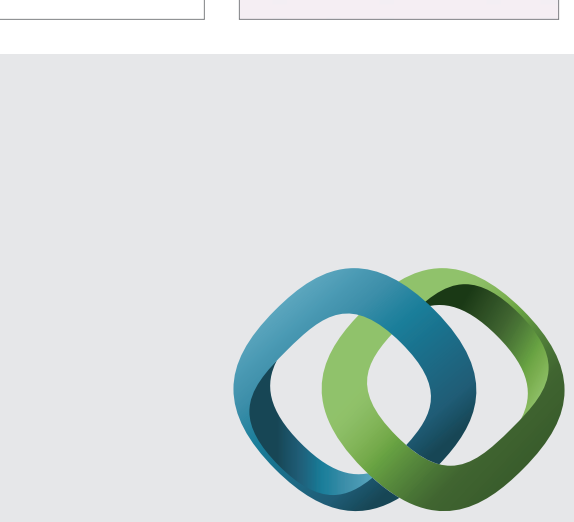

\section{Hindawi}

Submit your manuscripts at

http://www.hindawi.com
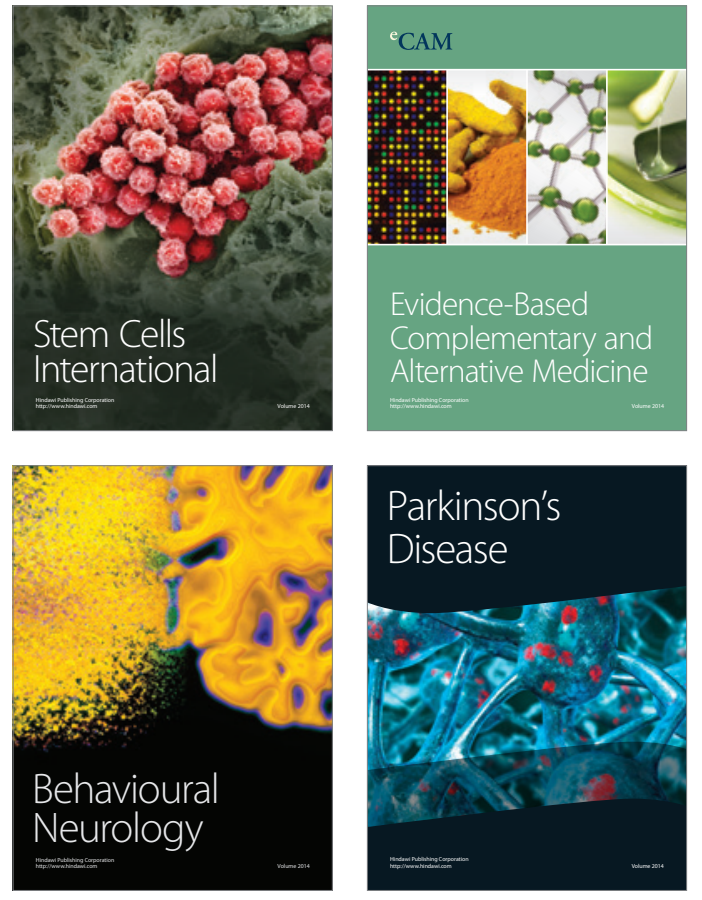
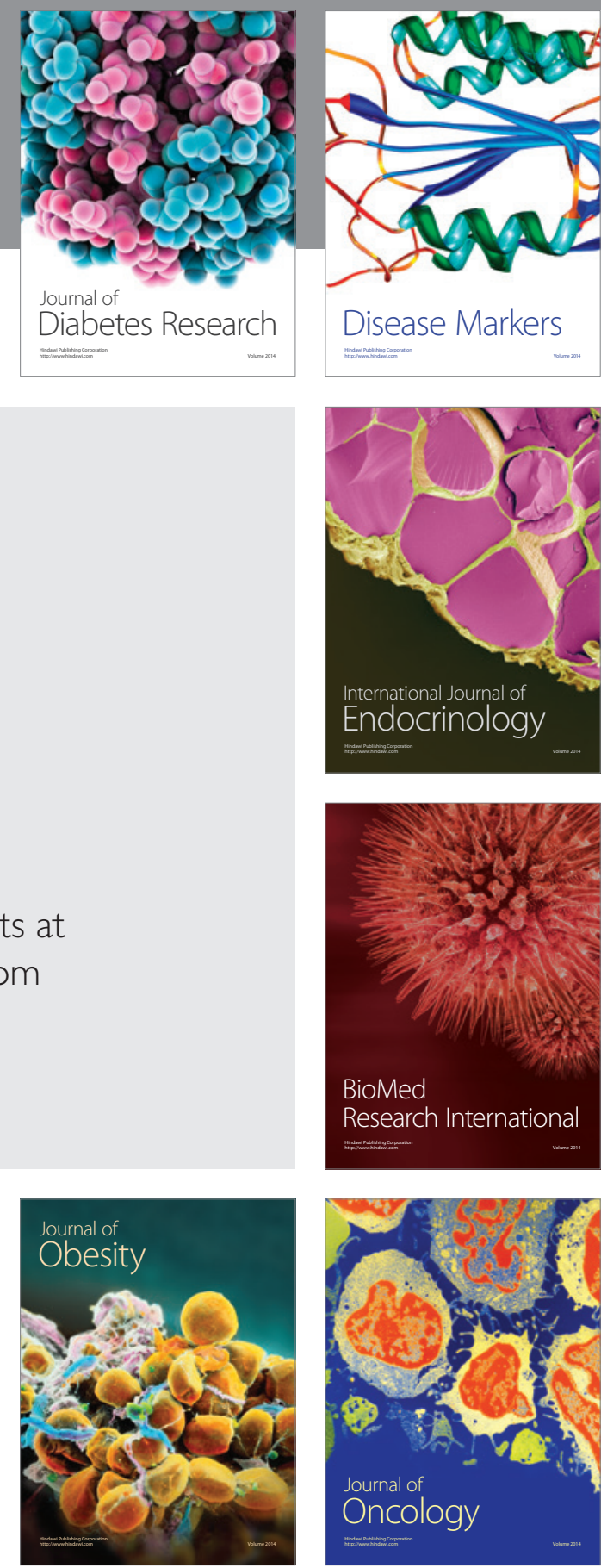

Disease Markers
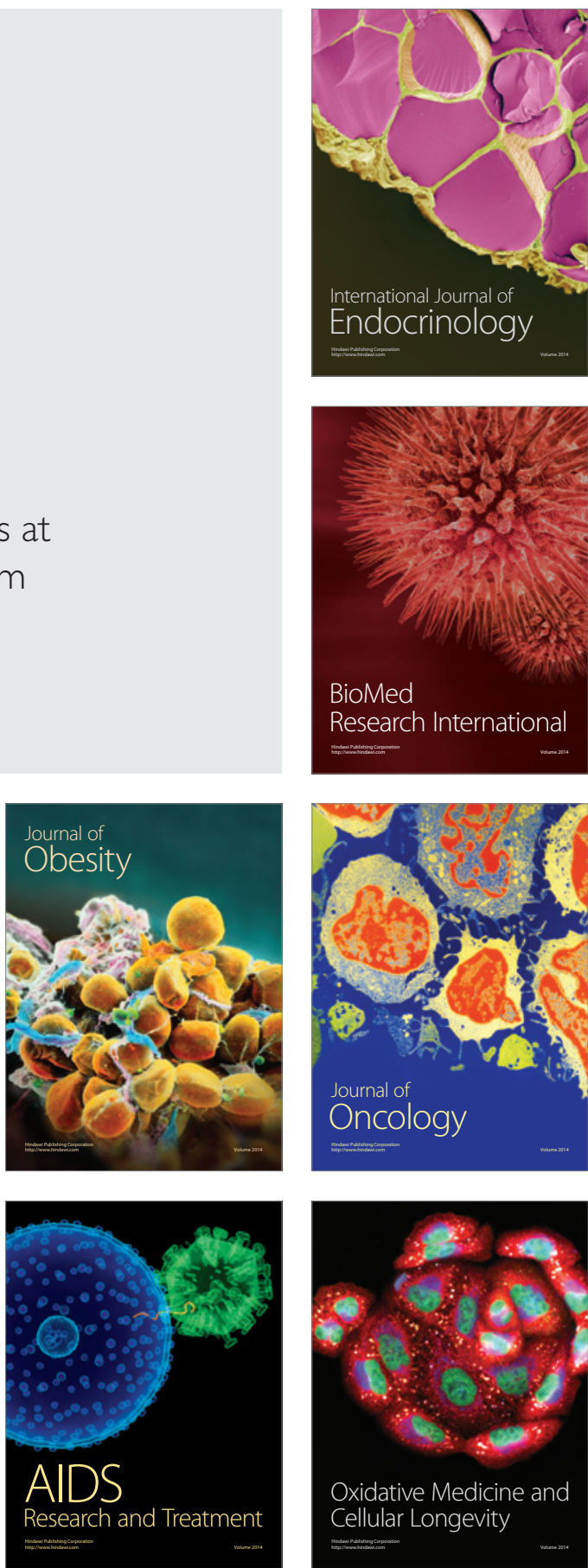